\title{
Analytical Study of Rotor Eccentricity Effects on Brushless Doubly Fed Machines Vibration
}

\author{
S. Abdi, E. Abdi, R. McMahon
}

\begin{abstract}
The Brushless Doubly Fed Machine (BDFM) with high reliability and robust structure demonstrates commercial and technical advantages both as a generator and motor for variable speed applications. As a generator it is particularly attractive to be used in offshore wind turbines where reliability improvement and maintenance cost reduction are the key factors in market growth. As a motor it may be utilized for adjustable speed drives. In this work, an analytical study has been performed on the BDFM's vibration due to the interaction of its fundamental magnetic fields, exerting bending forces in the back iron. The effects of rotor eccentricity on exacerbating the machine's vibration have been considered by assessing the stator back iron displacement function in the presence of rotor eccentricity. A prototype $250 \mathrm{~kW}$ BDFM built in frame size D400 was tested at different operating conditions in order to examine its noise and vibration levels. A set of measurements was conducted to assess the main vibration component frequencies developed by the machine at different rotor speeds. It is shown that the main vibration components are created by bending set-up in the back iron, rotor eccentricity, and the components with time and space harmonic natures. The results obtained from experimental tests agree with the analytical theory of BDFM vibration.
\end{abstract}

Index Terms - Beam theory; Brushless Doubly Fed Machine (BDFM); Displacement function; Rotor eccentricity; Rotor speed ripples; Space harmonics; Time harmonics; Vibration analysis.

\section{INTRODUCTION}

$\mathrm{T}$ HERE has been a dramatic increase in the size of wind turbines from $30 \mathrm{~kW}$ up to $10 \mathrm{MW}$ over the past 50 years [1]. To date, several generator concepts have been considered for offshore wind where there is a great wind power resource and hence significant future market growth is expected. These are permanent magnet generators, doubly fed induction generators, superconducting generators and high voltage DC generators [2]. To reduce the cost of energy from wind turbines, there is a need to improve availability and reduce operational and maintenance costs. Brushless Doubly Fed Machines (BDFMs) are an attractive solution for wind power generation as they offer promising design features and performance characteristics such as brushless operation, slip-ring elimination, fractionally rated power electronic converter and medium-speed operation. Other applications have also been reported for the BDFM, for example, in a flywheel energy storage system [3] and as a ship generator [4].

To date, several large BDFMs have been manufactured,

S. Abdi is with School of Engineering, University of East Anglia (UEA), Norwich, NR4 7TJ, UK (e-mail: s.abdi-jalebi@uea.ac.uk).

E. Abdi is with Wind Technologies Ltd, St. John's Innovation Centre, Cambridge, CB4 0WS, UK (e-mail: ehsan.abdi@gmail.com).

R. McMahon is with Warwick Manufacturing Group (WMG), University of Warwick, Coventry, CV4 7AL, UK (e-mail: r.momahon.1@warwick.ac.uk). for instance in China with a $200 \mathrm{~kW}$ machine [5], in Brazil with the design of a $75 \mathrm{~kW}$ machine [6], and in the UK with the largest BDFM ever reported. The later was designed and built in a frame size D400 and tested by the authors and some aspects of the machine's performance were reported in [7] and [8]. However, to achieve successful large scale BDFMs for wind generation application with competitive design and performance specifications over its counterparts, it is essential to improve the machine design including the vibration and acoustic noise characteristics.

The BDFM is operated with one of its windings, called the power winding $(\mathrm{PW})$, connected directly to the 3-phase grid. The other winding, called the control winding $(\mathrm{CW})$, may be either open circuited or short-circuited, thus operating similar to induction machines, but at two different speeds [9]. However, the desirable mode of operation for a BDFM is the 'synchronous mode' in which the control winding is connected to a variable voltage variable frequency converter as shown in Fig. 1 [7]. The machine's operating point is set as with a standard synchronous machine, but by adjusting the control winding frequency this operation can be at any rotor speed, leading to variable speed generator or drive operation [10].

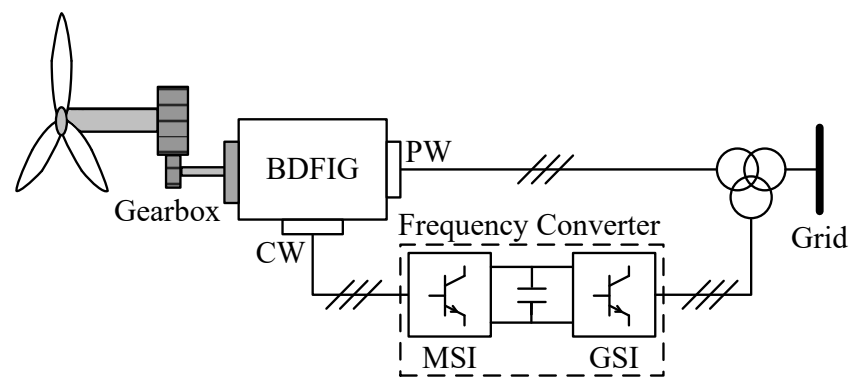

Fig. 1. A schematic of the wind turbine drive train with a BDFM as generator. MSI and GSI stand for machine side inverter and grid side inverter, respectively.

The magnetic fields in an induction machine exert significant forces on the machine's stator and rotor iron parts. Such forces can result in displacements and can be observed in the form of vibration and noise in the machine. In addition, because the BDFM has two main field components with different frequencies and pole numbers resulted from two stator windings, the vibration pattern is more complex in the BDFM than in the induction machine.

The presence of rotor eccentricity further increases the iron displacements and hence vibration levels by essentially modulating the magnetic fields produced by the stator windings and thus introducing further harmonic components [11]. Similar problem has been reported for other two-field electrical machines, such as dual stator induction machine [12]. In this work, an analytical study is conducted on the BDFM's modes of vibration caused by the interaction of its fundamental magnetic fields exerting bending forces in the 
back iron. The effects of rotor eccentricity, including both static and dynamic eccentricities, on exacerbating the machine's vibration are taken into account. Experimental tests were carried out on a large-scale BDFM built in frame size D400 at different operating conditions in order to examine its noise and vibration levels. A set of measurements was conducted to assess the main vibration frequencies at different rotor speeds. The results obtained experimentally support the analytical approach in predicting the main vibration components existed in the BDFM vibration spectrum.

\section{PREVIOUS WORKS ON BDFM VIBRATION}

There are only few studies carried out on the vibration analysis of BDFMs. Logan et. al. [13] derived equations for vibration components magnitudes generated by the $\mathrm{PW}$ and $\mathrm{CW}$ magnetic fields as functions of air-gap flux density, pole numbers and machine dimensions. In that study however, the effects of field harmonics and eccentricity were neglected. Abdi et. al. in [14] proposed a new parallel winding design for the stator PW and CW to mitigate the vibration level in the presence of rotor eccentricity. Analytical and experimental analysis of the BDFM vibration were performed in [15] noting that the vibration amplitude may be decreased if special attention is given to the choice of loops number in the rotor cage, number of power and control windings poles and careful design of the stator core. Dorrell et. al. in [16] proposed a number of rotor designs with suitable stator pole pair combinations in order to improve the BDFM design by reducing the unbalanced magnetic pull (UMP).

In order to minimise the magnetising currents in induction type machines, it is essential to construct the machine with shortest practical air gap. However, these induction machines experience strong magnetic fields across the air gap, which can cause considerable forces exerted on the iron parts of the machine. These can ultimately lead to time-varying displacements on the machine's surface and hence transmit noise to the surrounding air.

The UMP is an undesirable characteristic in dual stator machines by which vibrations and acoustic noise can be produced. It was shown in [16] that UMP occurs when the stator windings pole-pair numbers differ by one, so this vibration source can be avoided by careful stator winding design. However, it was shown in $[11,14]$ that another source of vibration known as 'bending set-up in the back iron' occurs in all BDFMs irrespective of pole-pair number combinations causing displacements of stator back iron and leading to bending mode vibration in the machine.

It was shown in [13] that the dominant term in the calculation of displacements in a BDFM is related to the difference of stator pole pair numbers $p_{1-} p_{2}$ and angular frequencies $\omega_{1}-\omega_{2}$. This term essentially represents the existence of two fundamental field components in the machine generated by stator windings with different frequencies and pole numbers. It was also shown that the vibration component with angular frequency $\omega_{1}-\omega_{2}$ has the greatest contribution in the vibration of an ideally constructed BDFM.

As with the induction machine, the eccentricity of the rotor further modulates the field patterns, and therefore increases vibration and noise levels in the machine [17]; however, these effects are not straightforward to precisely determine through analytical calculations. Nevertheless, it will be shown in this paper that in BDFMs with static and dynamic eccentricities, vibration components at angular frequencies of $\omega_{r}, \omega_{1-}-\omega_{2}$ and $\omega_{1-}-\omega_{2} \pm \omega_{r}$ are developed. The effects of eccentricity in the vibration spectrum are also discussed in section III.

There are other important factors that can contribute to the vibration and noise in the BDFM, such as the presence of time harmonics in stator and rotor winding currents, air gap magnetic field space harmonics, and the dynamics of the mechanical system (including natural frequencies of various components). These effects are present in the experimental results shown in section IV, but their analytical investigation is outside the scope of this paper.

\section{MAGNETIC FORCES AND RESULTING DISPLACEMENTS}

\section{A. Perfectly constructed BDFM:}

As mentioned in Section II, vibration caused by bending set-up in the back iron is occurred in BDFMs irrespective of pole pair number combinations causing stator back iron displacement and leading to bending mode vibration in the BDFM.

The magnetic field in a BDFM air gap comprises two fundamental field components, one with $2 p_{1}$ poles and the mean absolute flux density of $\bar{B}_{1}$ rotating at $\omega_{1} \mathrm{rad} / \mathrm{s}$, and another with $2 p_{2}$ poles and $\bar{B}_{2}$ flux density rotating at $\omega_{2}$. The net flux density is essentially the superposition of the above two field components and can be expressed as a function of time and space angle [18]:

$$
B(\theta, t)=\frac{\pi}{2}\left[\bar{B}_{1} \cos \left(p_{1} \theta+\omega_{1} t+\phi_{1}\right)+\bar{B}_{2} \cos \left(p_{2} \theta+\omega_{2} t+\phi_{2}\right)\right]
$$

where $\omega_{1}$ and $\omega_{2}$ are the frequencies of the two stator supplies, and $\phi_{1}$ and $\phi_{2}$ are phase angles. In (1) any harmonic field components generated by saturation, rotor structure, slotting, and rotor eccentricity are ignored.

In [13] a theoretical analysis of vibration patterns in the BDFM was proposed using beam theory as described for the induction machine by, for example, Alger [19]. Generally, this assumes that transverse deflections dominate shear deflections and that the underlying longitudinal strains are small, so that changes in curvature can be directly related to the bending moment on a given cross-section in a linear fashion [13]. Using this method, the forces exerted by the magnetic field are calculated and the resulting displacement of the iron is determined from the procedure illustrated in Fig. 2. The magnitudes of the main vibration components as function of the machine dimensions and pole numbers can then be obtained. The algebraic expression of vibration components gives an insight on how they may be changed to reduce vibration during the design of BDFMs and therefore having an analytical expression of the vibration pattern is important for the BDFM design optimisation.

Based on the above approach, the resulting displacement in the stator back iron from the exerted magnetic force produced by the air gap magnetic field of (1) can be calculated as [14]: 


$$
\begin{aligned}
& v(\theta, t)=-K_{v}\left[\frac{1}{\left(\left(2 p_{1}\right)^{2}-1\right)^{2}} \bar{B}_{1}^{2} \cos \left(2 p_{1} \theta+2 \omega_{1} t+2 \phi_{1}\right)\right. \\
& +\frac{1}{\left(\left(2 p_{2}\right)^{2}-1\right)^{2}} \bar{B}_{2}^{2} \cos \left(2 p_{2} \theta+2 \omega_{2} t+2 \phi_{2}\right) \\
& +\frac{2}{\left(\left(p_{1}-p_{2}\right)^{2}-1\right)^{2}} \bar{B}_{1} \bar{B}_{2} \cos \left(\left(p_{1}-p_{2}\right) \theta+\left(\omega_{1}-\omega_{2}\right) t+\left(\phi_{1}-\phi_{2}\right)\right) \\
& \left.+\frac{2}{\left(\left(p_{1}+p_{2}\right)^{2}-1\right)^{2}} \bar{B}_{1} \bar{B}_{2} \cos \left(\left(p_{1}+p_{2}\right) \theta+\left(\omega_{1}+\omega_{2}\right) t+\left(\phi_{1}+\phi_{2}\right)\right)\right]
\end{aligned}
$$

$K_{v}$ is dependent on material properties and machine geometry and expressed as [13]:

$$
K_{v}=\frac{3 D_{a} D_{c}^{3} \pi^{2}}{64 E_{y m} \mu_{0} y_{c}^{3}}
$$

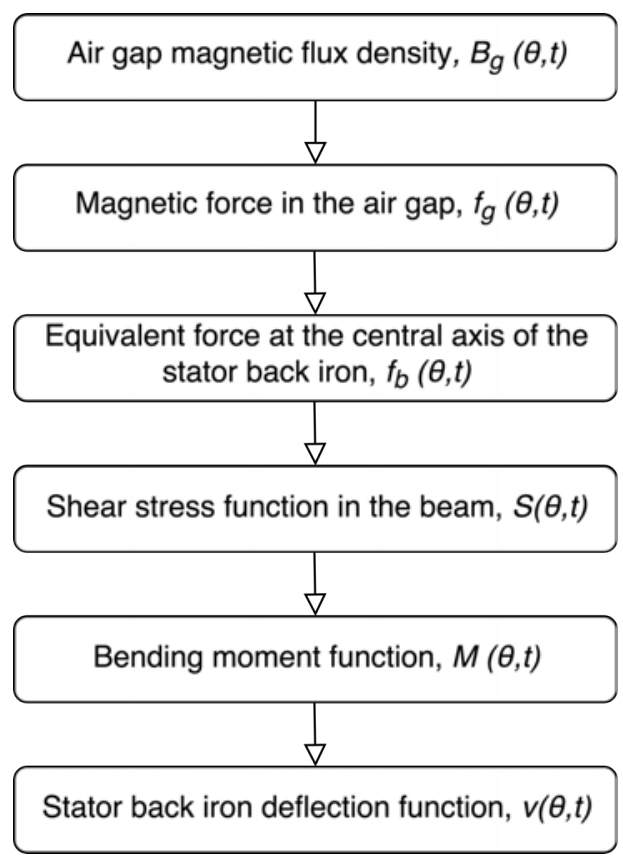

Fig. 2. A block diagram showing how stator back iron deflection is obtained using air gap flux density waveform [13].

where $D_{a}$ is the air gap diameter, $D_{c}$ is the median diameter of the stator back iron, $y_{c}$ is the back iron depth and $E_{y m}$ is the Young's modulus of the material. Hence, $K_{v}$ is constant for a particular BDFM. The full derivation of (2) can be found in [13]. Equation (2) comprises four terms, the first two of which are single field components, as would be expected in an induction machine. The latter two terms are dependent on the difference and sum of the pole pairs, respectively. Since each term is inversely proportional to the fourth power of the pole pairs, the term that includes the difference of pole pairs, i.e. the third term with angular frequency of $\omega_{1}-\omega_{2}$, can become relatively large in BDFMs with a small difference between power and control winding pole pairs. This will be investigated experimentally in Section $\mathrm{V}$.

\section{B. BDFM with rotor eccentricity:}

The previous section showed that a perfectly constructed BDFM experiences vibration modes in addition to those that would appear in an equivalent induction machine because of the interaction between two stator fields. In this section, the effect of rotor eccentricity is studied as a source of noise and vibration.
Rotor and stator eccentricity can essentially introduce additional components of flux with different pole numbers from those of the windings. Two types of eccentricity are considered in this analysis: static eccentricity where the central axes of the stator bore and the rotor shaft are offset, and dynamic eccentricity where the centre axis of rotor lamination stack is offset from the centre axis of rotor shaft. The air gap length as a result of eccentricity is:

$$
g(\theta, t)=g_{0}-g_{s} \cos \left(\theta+\phi_{s}\right)-g_{d} \cos \left(\theta+\omega_{r} t+\phi_{d}\right)
$$

where $g_{0}$ is the average air gap length, $g_{s}$ and $g_{d}$ are the amplitude of the static and dynamic eccentricity components respectively, and $\omega_{r}$ is the rotor angular velocity. $\phi_{s}$ and $\phi_{d}$ are arbitrary angles relative to the stator reference axis. The magnetic flux density in the air gap as a result of the surface magnetizing current density $J_{m}(\theta, t)$ may be derived from the Ampere's law as:

$$
B(\theta, t)=\mu_{0} g^{-1}(\theta, t) \frac{D_{a}}{2} \int J_{m}(\theta, t) d \theta
$$

where the MMF drops across the iron parts of the magnetic path are neglected. The inverse of air gap function in (4) can be expressed using Fourier series as:

$$
\begin{aligned}
g^{-1}(\theta, t) & =g_{0}^{-1}+g_{s 1}^{-1} \cos \left(\theta+\phi_{s 1}\right)+g_{d 1}^{-1} \cos \left(\theta+\omega_{r} t+\phi_{d 1}\right)+\ldots \\
& =g_{0}^{-1}\left[1+d_{s 1} \cos \left(\theta+\phi_{s 1}\right)+d_{d 1} \cos \left(\theta+\omega_{r} t+\phi_{d 1}\right)+\ldots\right]
\end{aligned}
$$

where $d_{s 1}$ and $d_{d 1}$ are the static and dynamic eccentricity coefficients, respectively. Given these coefficients are generally very small, $d_{s l}$ and $d_{d l}$ may be approximated to $g_{s} / g_{0}$ and $g_{d} / g_{0}$, respectively [20].

The BDFM magnetizing current density contains $p_{l}$ pole pair $\mathrm{PW}$ and $p_{2}$ pole pair $\mathrm{CW}$ components:

$J_{m}(\theta, t)=\hat{J}_{m 1} \cos \left(p_{1} \theta+\omega_{1} t+\phi_{1}\right)+\hat{J}_{m 2} \cos \left(p_{2} \theta+\omega_{2} t+\phi_{2}\right)$

After substituting (6) and (7) into (5), the components of the flux are shown in Table I, where

$$
\bar{B}_{i}=\frac{D_{a}}{\pi} \frac{g_{0}^{-1} \mu_{0}}{p_{i}} \hat{J}_{m i}
$$

AIR GAP MAGNETIC FLUX DENSITY COMPONENTS IN THE PRESENCE OF ROTOR ECCENTRICITY

\begin{tabular}{ccccc}
\hline $\boldsymbol{i}$ & Magnitude & Pole-pairs & Frequency & Phase \\
\hline 1 & $\bar{B}_{1}$ & $P_{1}$ & $\omega_{1}$ & $\phi_{1}$ \\
2 & $\bar{B}_{2}$ & $P_{2}$ & $\omega_{2}$ & $\phi_{2}$ \\
3 & $\bar{B}_{1} d_{s 1} / 2$ & $P_{1}-1$ & $\omega_{1}$ & $\phi_{1}-\phi_{s l}$ \\
4 & $\bar{B}_{1} d_{s 1} / 2$ & $P_{1}+1$ & $\omega_{1}$ & $\phi_{1}+\phi_{s l}$ \\
5 & $\bar{B}_{2} d_{s 1} / 2$ & $P_{2}-1$ & $\omega_{2}$ & $\phi_{2}-\phi_{s l}$ \\
6 & $\bar{B}_{2} d_{s 1} / 2$ & $P_{2}+1$ & $\omega_{2}$ & $\phi_{2}+\phi_{s l}$ \\
7 & $\bar{B}_{1} d_{d 1} / 2$ & $P_{1}-1$ & $\omega_{1}-\omega_{r}$ & $\phi_{1}-\phi_{d 1}$ \\
8 & $\bar{B}_{1} d_{d 1} / 2$ & $P_{1}+1$ & $\omega_{1}+\omega_{r}$ & $\phi_{1}+\phi_{d 1}$ \\
9 & $\bar{B}_{2} d_{d 1} / 2$ & $P_{2}-1$ & $\omega_{2}-\omega_{r}$ & $\phi_{2}-\phi_{d l}$ \\
10 & $\bar{B}_{2} d_{d 1} / 2$ & $P_{1}+1$ & $\omega_{2}+\omega_{r}$ & $\phi_{2}+\phi_{d 1}$ \\
\hline
\end{tabular}

Consequently, the displacement function of the stator back iron in the presence of rotor eccentricity can be derived from the procedure described in Fig. 2. Essentially, the 
exerted magnetic force produced by the air gap magnetic field components of (8) can be obtained from a series of integrations in order to derive the resultant back iron displacement. The displacement components that arise are summarized in Table II, neglecting those containing the product of two or more eccentricity coefficients (e.g. $d_{s 1 .} d_{s 2}$ ), which are relatively smaller than other terms. The magnitudes of displacement components given in Table II include the constant $K_{v}$ given in (3). The first four components given in rows 1-4 in Table II are also present in the analysis of displacements for a perfectly constructed BDFM given in (2). The remaining components (5-24 in Table II) are created from eccentricities. As previously noted, the displacement terms have magnitudes inversely proportional to the fourth power of the pole-pairs and thus it is those with low number of pole pairs that make significant contribution in the machine vibration.

TABLE II

DISPLACEMENTS COMPONENTS IN THE PRESENCE OF ROTOR ECCENTRICITY

\begin{tabular}{|c|c|c|c|}
\hline Comp & $\begin{array}{l}\text { Pole-pair } \\
\text { Number }\end{array}$ & Frequency & $\begin{array}{c}\text { Displacements Wave } \\
\text { Magnitude }\end{array}$ \\
\hline 1 & $2 p_{1}$ & $2 \omega_{1}$ & $K_{v} \bar{B}_{1}^{2} /\left(2 p_{1}\right)^{4}$ \\
\hline 2 & $2 p_{2}$ & $2 \omega_{2}$ & $K_{v} \bar{B}_{2}^{2} /\left(2 p_{2}\right)^{4}$ \\
\hline 3 & $p_{1}-p_{2}$ & $\omega_{1}-\omega_{2}$ & $K_{v} 2 \bar{B}_{1} \bar{B}_{2} /\left(p_{1}-p_{2}\right)^{4}$ \\
\hline 4 & $p_{1}+p_{2}$ & $\omega_{1}+\omega_{2}$ & $K_{v} 2 \bar{B}_{1} \bar{B}_{2} /\left(p_{1}+p_{2}\right)^{4}$ \\
\hline 5 & 1 & 0 & $K_{v} 2 d_{s 1} \bar{B}_{1}^{2}$ \\
\hline 6 & 1 & 0 & $K_{v} 2 d_{s 1} \bar{B}_{2}^{2}$ \\
\hline 7 & $2 p_{1}-1$ & $2 \omega_{1}$ & $K_{v} d_{s 1} \bar{B}_{1}^{2} /\left(2 p_{1}-1\right)^{4}$ \\
\hline 8 & $2 p_{1}+1$ & $2 \omega_{1}$ & $K_{v} d_{s 1} \bar{B}_{1}^{2} /\left(2 p_{1}+1\right)^{4}$ \\
\hline 9 & $2 p_{2}-1$ & $2 \omega_{2}$ & $K_{v} d_{s 1} \bar{B}_{2}^{2} /\left(2 p_{2}-1\right)^{4}$ \\
\hline 10 & $2 p_{2}+1$ & $2 \omega_{2}$ & $K_{v} d_{s 1} \bar{B}_{2}^{2} /\left(2 p_{2}+1\right)^{4}$ \\
\hline 11 & $p_{1}-p_{2}-1$ & $\omega_{1}-\omega_{2}$ & $K_{v} 2 d_{s 1} \bar{B}_{1} \bar{B}_{2} /\left(p_{1}-p_{2}-1\right)^{4}$ \\
\hline 12 & $p_{1}-p_{2}+1$ & $\omega_{1}-\omega_{2}$ & $K_{v} 2 d_{s 1} \bar{B}_{1} \bar{B}_{2} /\left(p_{1}-p_{2}+1\right)^{4}$ \\
\hline 13 & $p_{1}+p_{2}-1$ & $\omega_{1}+\omega_{2}$ & $K_{v} 2 d_{s 1} \bar{B}_{1} \bar{B}_{2} /\left(p_{1}+p_{2}-1\right)^{4}$ \\
\hline 14 & $p_{1}+p_{2}+1$ & $\omega_{1}+\omega_{2}$ & $K_{v} 2 d_{s 1} \bar{B}_{1} \bar{B}_{2} /\left(p_{1}+p_{2}+1\right)^{4}$ \\
\hline 15 & 1 & $\omega_{r}$ & $K_{v} 2 d_{d 1} \bar{B}_{1}^{2}$ \\
\hline 16 & 1 & $\omega_{r}$ & $K_{v} 2 d_{d 1} \bar{B}_{2}^{2}$ \\
\hline 17 & $2 p_{1}-1$ & $2 \omega_{1}-\omega_{r}$ & $K_{v} d_{d 1} \bar{B}_{1}^{2} /\left(2 p_{1}-1\right)^{4}$ \\
\hline 18 & $2 p_{1}+1$ & $2 \omega_{1}+\omega_{r}$ & $K_{v} d_{d 1} \bar{B}_{1}^{2} /\left(2 p_{1}+1\right)^{4}$ \\
\hline 19 & $2 p_{2}-1$ & $2 \omega_{2}-\omega_{r}$ & $K_{v} d_{d 1} \bar{B}_{2}^{2} /\left(2 p_{2}-1\right)^{4}$ \\
\hline 20 & $2 p_{2}+1$ & $2 \omega_{2}+\omega_{r}$ & $K_{v} d_{d 1} \bar{B}_{2}^{2} /\left(2 p_{2}+1\right)^{4}$ \\
\hline 21 & $p_{1}-p_{2}-1$ & $\omega_{1}-\omega_{2}-\omega_{r}$ & $K_{v} 2 d_{d 1} \bar{B}_{1} \bar{B}_{2} /\left(p_{1}-p_{2}-1\right)^{4}$ \\
\hline 22 & $p_{1}-p_{2}+1$ & $\omega_{1}-\omega_{2}+\omega_{r}$ & $K_{v} 2 d_{d 1} \bar{B}_{1} \bar{B}_{2} /\left(p_{1}-p_{2}+1\right)^{4}$ \\
\hline 23 & $p_{1}+p_{2}-1$ & $\omega_{1}+\omega_{2}-\omega_{r}$ & $K_{v} 2 d_{d 1} \bar{B}_{1} \bar{B}_{2} /\left(p_{1}+p_{2}-1\right)^{4}$ \\
\hline 24 & $p_{1}+p_{2}+1$ & $\omega_{1}+\omega_{2}+\omega_{r}$ & $K_{v} 2 d_{d 1} \bar{B}_{1} \bar{B}_{2} /\left(p_{1}+p_{2}+1\right)^{4}$ \\
\hline
\end{tabular}

In a 2/4 pole pair machine, as for the D400 BDFM, there are six components with a single pole pair waveform (i.e. comps. 5, 6, 12, 15, 16 and 22 in Table II) in addition to the main displacement component present in the ideal machine analysis (comp. 3 in Table II), that together give the following approximation for the back iron displacement:

$$
\begin{aligned}
& v(\theta, t)=2 K_{V}\left[\bar{B}_{1} \bar{B}_{2} \cos \left(\theta+\left(\omega_{1}-\omega_{2}\right) t+\left(\phi_{1}-\phi_{2}\right)\right)\right. \\
& +d_{s 1}\left(\bar{B}_{1}^{2}+\bar{B}_{2}^{2}\right) \cos \left(\theta+\phi_{s 1}\right) \\
& +\frac{d_{s 1}}{16} \bar{B}_{1} \bar{B}_{2} \cos \left(2 \theta+\left(\omega_{1}-\omega_{2}\right) t+\left(\phi_{1}-\phi_{2}+\phi_{s 1}\right)\right) \\
& +d_{d 1}\left(\bar{B}_{1}^{2}+\bar{B}_{2}^{2}\right) \cos \left(\theta+\omega_{r} t+\phi_{d 1}\right) \\
& \left.+\frac{d_{d 1}}{16} \bar{B}_{1} \bar{B}_{2} \cos \left(2 \theta+\left(\omega_{1}-\omega_{2}+\omega_{r}\right) t+\left(\phi_{1}-\phi_{2}+\phi_{d 1}\right)\right)\right]
\end{aligned}
$$

From (9) it can be realised that the most important vibration frequency components expected in the BDFM vibration spectrum are: $\omega_{r}, \omega_{1}-\omega_{2}$ and $\omega_{1}-\omega_{2} \pm \omega_{r}$. It should be noted that the vibration component with frequency signature of $\omega_{1}-\omega_{2} \mathrm{rad} / \mathrm{s}$ is created due to both bending set-up in the back iron (as shown in (2)) and eccentricity (as shown in (9)). Hence, the two mechanisms superimpose but not necessarily with the same phase over the operating speed range.

\section{EXPERIMENTAL ASSESSMENT OF VIBRATION IN THE BDFM}

Table III gives details of the $250 \mathrm{~kW}$ BDFM used in this study. Both stator PW and CW are connected in delta. The rotor is a nested-loop design comprising six nests, each with five loops [21]. All rotor loops are terminated with a common end-ring at one end only [22].

TABLE III

SPECIFICATIONS OF THE $250 \mathrm{KW}$ D400 BDFM

\begin{tabular}{ll} 
Frame size & 400 \\
PW pole number & 4 \\
PW rated voltage & $690 \mathrm{~V}$ at $50 \mathrm{~Hz}$ (delta) \\
PW rated current & $178 \mathrm{~A}$ (line) \\
CW pole number & 8 \\
CW rated voltage & $620 \mathrm{~V}$ at $18 \mathrm{~Hz}$ (delta) \\
CW rated current & $73 \mathrm{~A}($ line) \\
Speed range & $500 \mathrm{rpm} \pm 36 \%$ \\
Rated torque & $3670 \mathrm{Nm}$ \\
Rated power & $250 \mathrm{~kW}$ at $680 \mathrm{rpm}$ \\
Air gap diameter & $439 \mathrm{~mm}$ \\
Back iron depth & $54 \mathrm{~mm}$ \\
Median diameter of stator back iron & $636 \mathrm{~mm}$ \\
Stack length & $820 \mathrm{~mm}$ \\
\hline
\end{tabular}

\section{A. Vibration test set-up}

The $250 \mathrm{~kW}$ BDFM is shown in Fig. 3 on the experimental rig. The machine's control system includes grid-side inverter (GSI) and machine-side inverter (MSI). The GSI was developed with an embedded control system to stabilize the DC-link and synchronize to the $690 \mathrm{~V}$ grid voltage. The MSI was developed to control the PW real and reactive power using a Speedgoat controller [7].

A set of measurements was conducted on the machine to validate the vibration analysis carried out in the previous section. The machine was instrumented with a number of accelerometers positioned on the bedplate, frame and terminal box of the machine, as shown in Fig. 4, and was operated in the synchronous mode of operation at a speed range of 320-620 rpm. Vibration was measured using Bruel 
\& Kjaer 2260 instruments from the drive end of the machine with the specifications shown in Table IV.

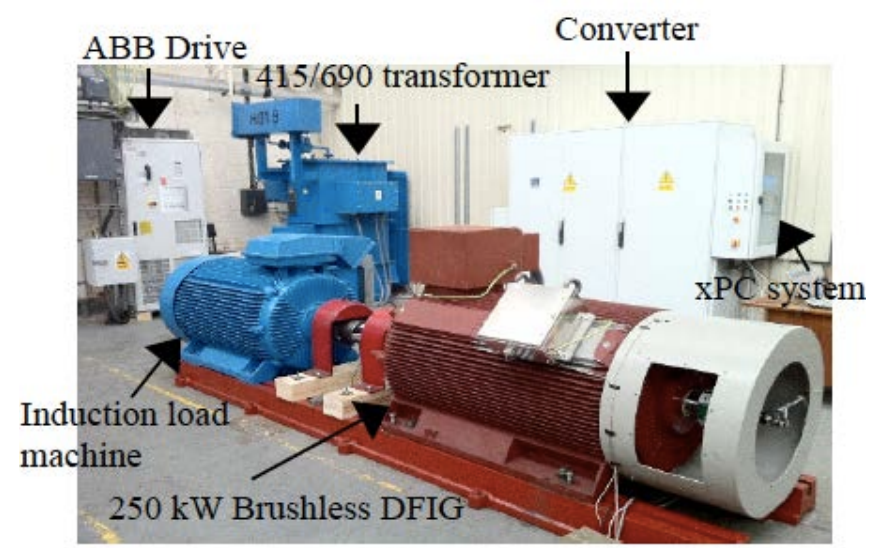

Fig. 3. $250 \mathrm{~kW}$ BDFM and the load machine on test rig.

The accelerometers' signals were digitised using a data logger controlled by LabVIEW software. The fast Fourier transform of the signals were also computed using a built-in algorithm. The measured averaged root mean square $(\mathrm{rms})$ vibration velocity over a range of operating speeds is shown in Fig. 5.

As can be seen from Fig. 5, for the rotor speed between $540-680 \mathrm{rpm}$, the $\mathrm{rms}$ values of vibration velocity remain within the range of $2.87-4.01 \mathrm{~mm} / \mathrm{s}$. This is close to the standard limit, based on the ISO 10816 standard for vibration assessment of a $250 \mathrm{~kW}$ class $\mathrm{M}$ electrical machine. Nevertheless, for the operating speed range of 320$520 \mathrm{rpm}$, the measured vibration $\mathrm{rms}$ values are between 5.15 and $12.70 \mathrm{~mm} / \mathrm{s}$, which is above the tolerable limit.

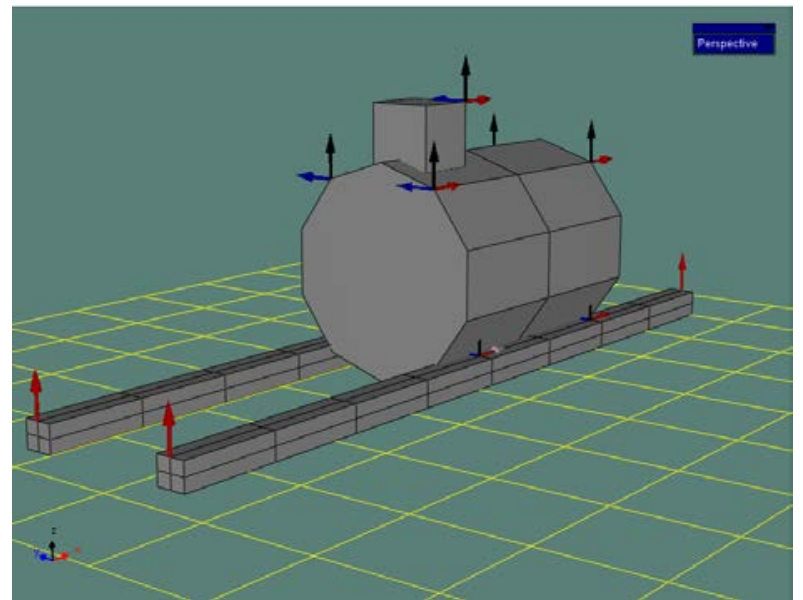

Fig. 4. Location of accelerometers on the BDFM test bed for vibration measurements.

TABLE IV

SPECIFICATIONS OF THE VIBRATION MEASUREMENT INSTRUMENTS

\begin{tabular}{lc} 
Instrument model & Bruel \& Kjaer 2260 \\
Input type & Vibration \\
Full scale & $117.6 \mathrm{~m} / \mathrm{s}^{2}$ \\
Frequency span & $312.5 \mathrm{~Hz}$ \\
Centre frequency & $157.47 \mathrm{~Hz}$ \\
Frequency resolution & $0.732 \mathrm{~Hz}$ \\
High pass filter & $0.1 \mathrm{~Hz}$ \\
Sensitivity & $845 \mu \mathrm{V} / \mathrm{m} / \mathrm{s}^{2}$ \\
\hline
\end{tabular}

\section{B. Measured vibration spectra}

The spectra of vibration amplitudes in $\mathrm{dB}$ have been obtained for the $250 \mathrm{~kW}$ BDFM at the operating conditions where the machine's vibration velocity is at its highest level. Fig. 6 (a) shows the vibration spectrum at the rotor speed of $440 \mathrm{rpm}$ and the PW and CW supplied frequencies of $50 \mathrm{~Hz}$ and $6 \mathrm{~Hz}$, respectively. The supply voltages were set to give magnetic loadings of 0.32 and $0.38 \mathrm{~T}$ for the $\mathrm{PW}$ and $\mathrm{CW}$, respectively, in order to achieve the nominal field strength in the machine air gap.

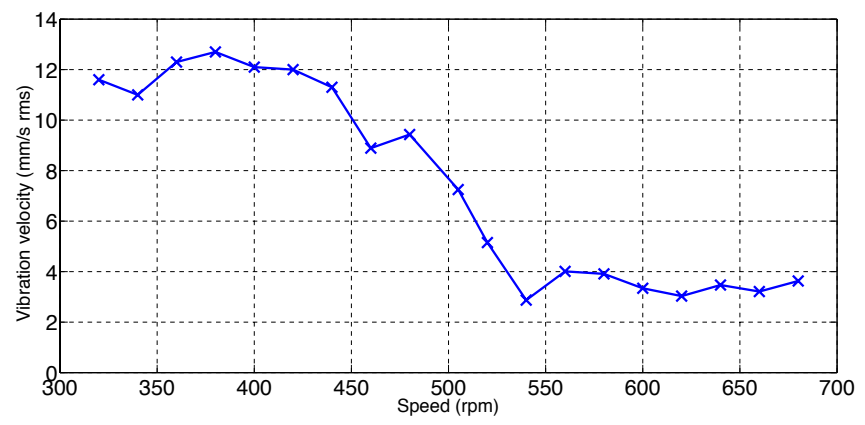

Fig. 5. Vibration velocity over the BDFM operating speed range.

Air gap non-uniformity was present in the prototype 250 $\mathrm{kW}$ BDFM, partly due to the rotor shape not being purely circular and partly due to the presence of rotor eccentricity. Experimental measurements showed that the rotor axis was off centre by approximately $15 \%$ of the air gap length. In addition, rotor whirling was observed when experimental tests were carried out at rated operating conditions, showing the presence of both static and dynamic eccentricities at normal operation.

Fig. 6 (a) shows three distinct peaks at 56, 48.7 and 63.3 $\mathrm{Hz}$ frequencies. The $56 \mathrm{~Hz}$ vibration component is consistent with $\omega_{1}-\omega_{2}$ component predicted in section III-A as the main vibration component caused by the bending set-up in the back iron of the ideally constructed BDFM. It is also consistent with $\omega_{1}-\omega_{2}$ component predicted in section III$\mathrm{B}$ as a result of rotor eccentricity. The other two frequencies, i.e. $48.7 \mathrm{~Hz}$ and $63.3 \mathrm{~Hz}$, however, are consistent with $\omega_{1}-$ $\omega_{2} \pm \omega_{r}$ vibration components created solely by the presence of rotor eccentricity. It is important to note that there is always a degree of rotor eccentricity present in a real machine due to manufacturing imperfection, which may cause significant vibration and noise issues in the BDFM as discussed in Section II.

Fig. 6 (b) shows the vibration spectrum at the rotor speed of $320 \mathrm{rpm}$ and the PW and CW supplied frequencies of 50 $\mathrm{Hz}$ and $18 \mathrm{~Hz}$, respectively. The main peak vibration frequencies are 68,63 and $73.3 \mathrm{~Hz}$, which correspond to $\omega_{1}-\omega_{2}$ and $\omega_{1}-\omega_{2} \pm \omega_{r}$, similar to what was found at $440 \mathrm{rpm}$.

The time and space harmonic contents in the BDFM torque, PW and CW currents, and active powers and their contribution in the machine vibration were studied in [23], [24]. Fig. 6 also demonstrates these harmonic-driven sources of vibration, which are denoted with different colours and numbers. Table $\mathrm{V}$ shows different vibration mechanisms and their associated numbers and colours. These additional vibration components generated from harmonic effects can exacerbate the vibration and noise levels and therefore, special design considerations such as rotor design optimisation and use of magnetic wedges in rotor slot openings need to be employed to reduce the harmonic 
effects.

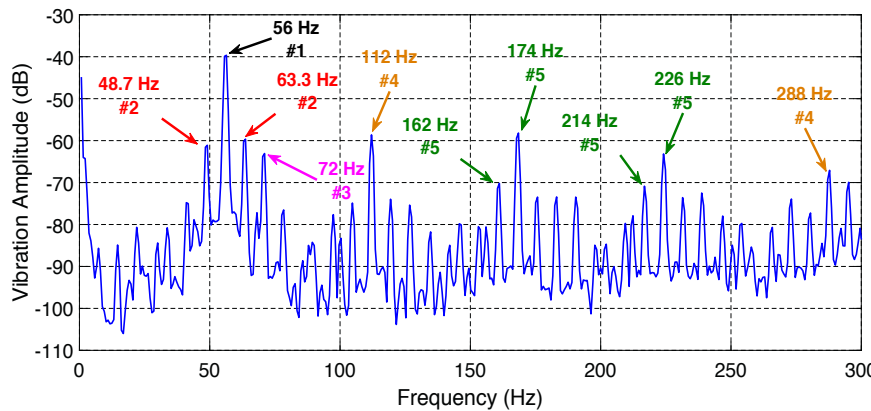

(a) $440 \mathrm{rpm}$ rotor speed

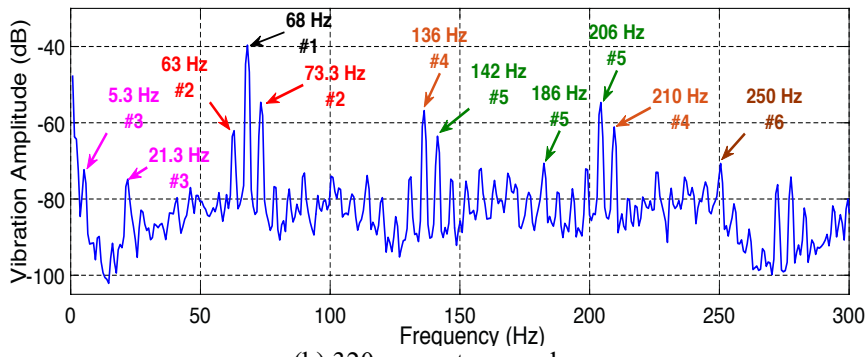

(b) $320 \mathrm{rpm}$ rotor speed

Fig. 6: Vibration amplitude spectrum at the machine's drive end at $0 \mathrm{~kW}$ (no-load), $100 \mathrm{kVAR}$, (a) $440 \mathrm{rpm}$, (b) $320 \mathrm{rpm}$

The vibration spectrum for a range of synchronous speeds was also obtained where the output active and reactive power were kept constant at $230 \mathrm{~kW}$ and $98 \mathrm{kVAR}$, respectively. For each speed, the three dominant frequencies with largest magnitudes were determined and are shown in Fig. 7. The solid, dashed and dotted lines in Fig. 7 correspond to $\omega_{1}-\omega_{2}, \omega_{1}-\omega_{2}+\omega_{r}$, and $\omega_{1}-\omega_{2}-\omega_{r}$, respectively.

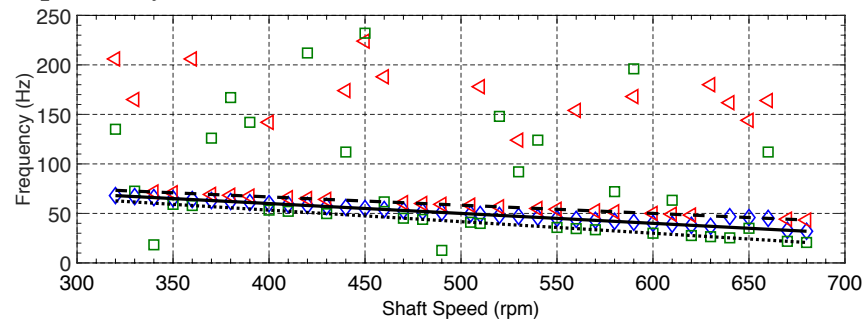

Fig. 7: Dominant frequencies in the vibration spectrum. For each speed the diamond, triangle and rectangle are the frequencies of largest, second largest and third largest components, respectively. The solid, dashed and dotted lines correspond to $\omega_{1}-\omega_{2}, \omega_{1}-\omega_{2}+\omega_{r}$, and $\omega_{1}-\omega_{2}-\omega_{r}$, respectively.

As can be seen, the largest displacement component at most speeds has the frequency of $\omega_{1}-\omega_{2}$, which corresponds to the source of vibration that includes the effects of both back iron bending set-up and rotor eccentricity. There are also reasonable correlations between the frequencies of second and third largest displacement components and the predicted rotor eccentricity vibration sources with $\omega_{1}-\omega_{2}+\omega_{r}$, and $\omega_{1}-\omega_{2}-\omega_{r}$, respectively. However, the variation in the frequency of second and third largest components seen in Fig. 7 suggests that other vibration mechanisms are taking part in the BDFM's vibration and noise patterns. These frequencies correspond mostly to the vibration mechanisms noted in Table V.

\section{CONCLUSIONS}

The BDFM is an attractive generator system for use in wind power generation particularly offshore installations as it offers significant reliability improvement as well as cost reduction when the overall wind turbine drive train is considered

TABLE V

THE ASSOCIATED COLOUR TO EACH SOURCE OF VIBRATION FREQUENCY IN FIG. 10

\begin{tabular}{llc} 
No & Vibration mechanism & $\begin{array}{c}\text { Associated colour } \\
\text { in Fig. 6 }\end{array}$ \\
\hline 1 & $\begin{array}{l}\text { Bending set-up in the back iron and } \\
\text { rotor eccentricity }\end{array}$ & Black \\
2 & Rotor eccentricity & Red \\
3 & Speed variation & Purple \\
4 & Load machine's control drive & Orange \\
5 & Space harmonics & Green \\
6 & PW and CW time harmonics & Brown \\
\hline
\end{tabular}

In this paper, various vibration mechanisms present in the BDFM's main mode of operation, the synchronous mode, were studied. It was shown that one of the main sources of vibration is created by bending set-up in the back iron, which occurs in any BDFM irrespective of pole pair combinations, causing a stator back iron displacement. It was also shown analytically that the displacement component with an angular frequency and pole-pair number of $\omega_{1}-\omega_{2}$ and $p_{1}-p_{2}$ (e.g. 4-pole displacement component for a $4 / 8$ pole prototype BDFM) can become very large in BDFMs with a small difference between power and control winding pole pairs and hence is the dominant vibration component in an ideally-constructed BDFM. In addition, it was shown that the rotor eccentricity introduces additional components of back iron displacement and results in BDFM vibration with the dominant frequencies of $\omega_{1}-\omega_{2}$ and $\omega_{1}-\omega_{2} \pm \omega_{r}$ and pole-pair number $\left|p_{1}-p_{2} \pm 1\right|$ (e.g. 2-pole displacement component for a $4 / 8$ pole BDFM).

A set of vibration tests were carried out on the prototype BDFM in order to assess the machine's vibration pattern. The experimental results confirmed the dominant vibration frequencies of $\omega_{1}-\omega_{2}$ and $\omega_{1}-\omega_{2} \pm \omega_{r}$ as predicted analytically for an eccentric BDFM. A degree of air gap nonuniformity was present in the prototype machine due to the uneven air gap length caused by manufacturing tolerance as well as rotor eccentricity.

Therefore, it is essential to implement appropriate design considerations in order to mitigate the vibration and noise levels before a large-scale BDFM is constructed for wind turbine drive trains. These may include increasing the air gap length, introduction of damping in the rotor winding, introduction of damping in the stator winding with parallel paths, and isolation of the stator frame from the stator core.

\section{REFERENCES}

[1] Global Wind Energy Council., 'Global Wind Report 2018' (GWEC, 2019), pp. 22-30.

[2] Z. Zhang, A. Matveev, R. Nilssen, A. Nysveen, 'Ironless PermanentMagnet Generators for Offshore Wind Turbines', IEEE Transactions on Industry Applications, Vol. 50, June 2014, pp. 1835-1846.

[3] A. C. Ferreira, R. M. Stephan, M. Araujo, 'Compensating characteristics of a brushless doubly-fed machine' IEEE International Symposium on Industrial Electronics, vol. 1, 2003, pp. 375-378.

[4] F. Xiong, X. Wang, 'Design and performance analysis of a brushless doubly-fed machine for stand-alone ship shaft generator systems' 
International Conference on Electrical and Control Engineering, 2011, pp. 2114-2117.

[5] H. Liu and L. Xu, "Design and performance analysis of a doubly excited brushless machine for wind power generator application." IEEE International Symposium on Power Electronics for Distributed Generation Systems, 2010, pp. 597 - 601.

[6] R. Carlson, H. Voltolini, F. Runcos, P. Kuo-Peng, and N. Baristela, "Performance analysis with power factor compensation of a $75 \mathrm{kw}$ brushless doubly fed induction generator prototype." IEEE International Conference on Electric Machines and Drives, 2010.

[7] E. Abdi, R. McMahon, P. Malliband, S. Shao, M. Mathekga, P. Tavner, S. Abdi, A. Oraee, T. Long, and M. Tatlow, "Performance analysis and testing of a $250 \mathrm{kw}$ medium-speed brushless doubly fed induction generator," Renewable Power Generation, IET, vol. 7, no. 6, pp. $631-638,2013$.

[8] T. Long; S. Shao; P. Malliband; E. Abdi; R. A. McMahon,' Crowbarless Fault Ride-Through of the Brushless Doubly Fed Induction Generator in a Wind Turbine Under Symmetrical Voltage Dips', IEEE Transactions on Industrial Electronics, Vol. 60, Issue 7, 2013.

[9] T. Strous, X. Wang, H. Polinder, J. Ferreira, 'Brushless doubly fed induction machines: Magnetic field analysis', IEEE Transactions on Magnetics, Vol. 52, No. 11, November 2016.

[10] S. Shao, E. Abdi, R. McMahon, 'Low-cost variable speed drive based on a brushless doubly fed motor and a fractional unidirectional converter', IEEE Transactions on Industrial Electronics, Vol. 59, No. 1, Jan 2012.

[11] J. Li, D. Choi, and Y. Cho, 'Analysis of rotor eccentricity in switched reluctance motor with parallel winding using fem'. IEEE Transactions on Magnetics, vol. 45, pp. 2851 - 2854, 2009.

[12] Munoz, A.R., Lipo, T.A.: 'Dual stator winding induction machine drive', IEEE Trans. Ind. Appl., 2000, 36, pp. 13691379.

[13] T. Logan, R. McMahon, and K. Seffen, 'Noise and vibration in brushless doubly fed machine and brushless doubly fed reluctance machine,' IET Electric Power Applications, vol. 7, pp. 1 - 10, 2014.

[14] S. Abdi, E. Abdi, R. McMahon, 'A Study of Unbalanced Magnetic Pull in Brushless Doubly Fed Machines' IEEE Transactions on Energy Conversion, vol. 30, pp. 1218 - 1227, 2015.

[15] F. Runcos, R. Carlson, N. Sadowski, P. Kuo-Peng, H. Voltolini, 'Performance and vibration analysis of a $75 \mathrm{~kW}$ brushless doubly fed induction generator prototype'. IEEE Industry Applications Conference, USA 2006

[16] Dorrell, D. Knight, A. Betz, 'Issues with the design of brushless doubly-fed reluctance machines: unbalanced magnetic pull, skew and iron losses'. 2011 IEEE Int. Electric Machines and Drives Conf. (IEMDC), 2011, pp. 663-668.

[17] D. Dorrell and A. Smith, 'Calculation of U.M.P in induction motors with series or parallel winding connections,' IEEE Trans. Energy Conversion, vol. 9, no. 2, pp. 304-310, Jul. 1994.

[18] R.A. McMahon, P. Roberts, X. Wang, P. J. Tavner' 'Performance of BDFM as generator and motor', IET Electric Power Application, Vol. 153, Issue 2, pp. 289-299, 2006

[19] Alger, P.L., 'The nature of polyphase induction machines', John Wiley \& Sons, New York, 1951.

[20] D. Dorrell, W. Thomson, S. Roach, 'Analysis of air gap flux, current and vibration signals as a function of the combination of static and dynamic airgap eccentricity in 3-phase induction motors', IEEE Transactions on Industry Applications, Vol 33, No. 1, January 1997.

[21] F. Barati, S. Shao, E. Abdi, H. Oraee, R. McMahon, 'Generalized vector model for the brushless doubly fed machine with a nested-loop rotor', IEEE Transactions on Industrial Electronics, Vol. 58, No. 6, June 2011.

[22] R. McMahon, P. Tavner, E. Abdi, P. Malliband, and D. Barker, 'Characterising brushless doubly fed machine rotors,' IET Electric Power Applications, vol. 7, pp. 535 - 543, 2013.

[23] F. Blazquez, C. Veganzones, D. Ramirez, and C. Platero, 'Characterization of the rotor magnetic field in a brushless doubly-fed induction machines,' IEEE Trans. Energy Conversion, vol. 24, no. 3, pp. 599-607, Sep. 2009.

[24] S. Abdi, D. Llano, E. Abdi, P. Malliband, R. McMahon, 'Experimental analysis of noise and vibration for large brushless doubly fed machines', IET The Journal of Engineering, vol. 2017, pp. 724-728, 2017.

\section{BIOGRAPHIES}

Salman Abdi received the B.Sc. degree from Ferdowsi University, Mashhad, Iran, in 2009, and the M.Sc. degree from the Sharif University of Technology, Tehran, Iran, in 2011, both in electrical engineering. He then completed the Ph.D. degree in electrical machines design, modeling and optimization from Cambridge University, Cambridge, U.K, in 2015. He was appointed as a Research Fellow in Cambridge University and Warwick University (2015-2017) and became a lecturer in Electrical Engineering at Coventry University (2017-2019). He is currently an Assistant Professor in Electrical Engineering at the University of East Anglia (UEA), Norwich, UK. His main research interests include electrical machines and drives for renewable power generation and automotive applications.

Ehsan Abdi (SM'12) received the B.Sc. degree from the Sharif University of Technology, Tehran, Iran, in 2002, and the M.Phil. and Ph.D. degrees, from Cambridge University, Cambridge, U.K., in 2003 and 2006, respectively, all in electrical engineering. He is currently the Managing Director of Wind Technologies Ltd., Cambridge, where he has been involved with commercial exploitation of the brushless doubly fed induction generator technology for wind power applications. He became a Senior Member of the IEEE in 2012. His main research interests include electrical machines and drives, renewable power generation, and electrical measurements and instrumentation.

Richard McMahon received the B.A. degree in electrical sciences and the Ph.D. degree from the University of Cambridge, Cambridge, U.K., in 1976 and 1980, respectively. Following postdoctoral work on semiconductor device processing, he became a University Lecturer in electrical engineering in 1989 with the Engineering Department, University of Cambridge, where he was a Senior Lecturer in 2000. In 2016, he was with the Warwick Manufacturing Group, University of Warwick, Coventry, U.K., as a Professor of power electronics. His current research interests include electrical drives, power electronics, and semiconductor materials. 